\title{
Integrated ICTs for Water Basins Management in Southern Africa: Systematic Review and Meta-analyses for Perceived Relevance Criteria
}

\author{
H. Mongi ${ }^{1}$, M. Meinhardt ${ }^{2}$ \\ ${ }^{1}$ Department of Information Systems, University of Dodoma, Tanzania; \\ ${ }^{2}$ Institute of Geography, Geographic Information Science, University of Jena, Germany
}

\begin{abstract}
User-focused design and an implementation of a computer-based Information System (IS) or Information Technology (IT) are considered to play a key role in enhancing adoption, supporting activities and contributing to the sector specific sustainability goals. However, there are general concerns over the practical applications derived from records of failure rates of IS/IT projects in the developing world. This paper aggregates and analyzes stakeholders' perceived usefulness criteria that were documented from water basin focusing on IS and related projects in Southern Africa. Systematic literature reviews and meta-analysis were adopted for data collection and analyses. Literature with academic, practice and hybrid viewpoints was collected from five water basins in Southern Africa. Designed data collection flow chart guided the search for appropriate literature. Analyses of the data were performed by using Statistical Package for Social Sciences (SPSS). Results of the search were classified and presented basing on the domain, yearly waves from 2000 to 2015 , trans-basin nature and basin of focus. Literature was distributed across the classes at different magnitudes. The study has found out that relevance criteria as measure of usefulness have been incorporated in designing and implementing the IS/IT projects in the river basins. However, incorporation of relevance criteria was periodically increasing with technological advancement and increasing complexity of managing the water basins. In general, it was responsive to increasing challenges of water resources in the developing countries. This anticipated better results at the levels of output, outcome and impacts of IS/IT projects in the Southern Africa. The study concludes that the current trends of incorporation of the relevance criteria in designing and implementing the IS/IT projects on water resources are potential for impact-based interventions in Southern Africa.
\end{abstract}

\section{Keywords}

Water basins, integrated ICTs, Southern Africa, relevance criteria, meta-analysis.

Mongi, H. and Meinhardt, M. (2016) "Integrated ICTs for Water Basins Management in Southern Africa: Systematic Review and Meta-analyses for Perceived Relevance Criteria ", AGRIS on-line Papers in Economics and Informatics, Vol. 8, No. 2, pp. 103-110. ISSN 1804-1930. DOI: 10.7160/aol.2016.080208.

\section{Introduction}

Relevance judgment, as a formal evaluation, is normally based on criteria. A set of criteria is usually established over time and should be known by the key stakeholders who make use of them. A rigorous measurement of an object's relevance, primarily, depends on validity and reliability. The latter two terms, respectively, describe the accuracy of a measurement as well as its ability to repeatedly produce the same results under similar conditions (Wholey et al, 2010). Rapid deployment of Information and Communication Technologies (ICTs) to support management of water resources in the developing world is among the efforts to address the challenges facing this critical resource for life. However, in Africa and developing countries in general, there are reports showing that ICT for Development projects were not well performing (Heeks, 2003; Dodson et al., 2012). Among the reasons associated with this status were inadequate involvement of stakeholders - hence lack of ownership, inadequate link between a problem and solution that ICT is placed to contribute and generally donor dependency. All of these contribute to lack of sustainability of projects and eventually the way they addressed challenges facing the target sector. Consequently, recurring observations have triggered a question: "How relevant were the ICTs for development 
in Africa?" In attempts to answer the question, it is observed that intuitive relevance (or judgment based on common sense) has often become dominant over "inferential relevance", therefore, producing answers with inadequate validity and reliability. Usage of the term "relevance" in intuitive way somehow does not distinguish it from any other English word. Within these circumstances, the "inferential side" of relevance is often ignored. Ambiguity associated with this kind of usage has, eventually, raised the level of concerns over validity and reliability of conclusions made on ICT relevance in Africa.

The role of ICTs for addressing challenges of shrinking water resources is as sound as the importance of water itself. Water resources are used in everyday life for agriculture, household and industry consumption. However, at basin levels, water and agriculture forms a clearer nexus. Water and agriculture are inter-related sectors of a significant importance in developing countries. Agriculture remains to be the engine of economies with water supporting irrigation for agricultural growth and poverty reduction (van Koppen et al., 2005). One of the basic characteristics of water basins in Southern Africa is that availability of suitable irrigable soils along the international rivers is, in general, much greater than the availability of water to support such irrigation (Nakayama, 2003). Inadequate water supply is caused by both traditional and emerging challenges. Traditional challenges have been the population growth and urbanization. While the former drives overutilization beyond threshold to meet the needs of increasing human population, the later is extending fragile resources, increasing pollution from industries and unplanned urban settlements (Kgathi et al., 2006). Amid these challenges, is climate change, which is a factor playing a compounding role making the water basins even more fragile.

More than $90 \%$ of water basins in Southern Africa are trans-boundary (Jansky, et al., 2005). The management of vital water resources in these basins is challenged by inadequate: (i) Participation of users; (ii) Coordination of decision-making; and (iii) Control. Technological tools are considered among solutions to address these challenges facing water basins, which are potential areas for agriculture and forestry across the world. Technologies for collecting data and processing them into information, disseminating information and creating as well as transforming knowledge into impactful actions, are being embraced across the scales and dimensions of the ecosystems. Innovative combination of modest and advanced technologies including ICTs is also being tested and or used. Examples are the usage of radio networked with remote sensors; possibility of combining robots with sensors and other software platforms; the Internet web-portals and mobile phones; or the internet web-portals, remote sensors and the higher end mobile phones. User-focused designing and implementing the ICTs is generally considered to play a key role in enhancing adoption, supporting activities as well as contributing approach to meeting the sector specific sustainability goals. However, there are general concerns over the practical applications derived from the records of the failure rates of ICT projects in the developing world. One of the reasons is inadequate involvement of users and thereby not incorporating their needs during the design and implementation phases. Consequently, there is often a missing link between the strategic objectives, processes and the anticipated outcome of such projects.

The Technology Acceptance Model (TAM) which was developed in the late 1980s, has for the last two decades provided a framework for understanding the technology adoption among users. Davis (1989) suggested that, the technology acceptance depends on two main constructs: a perceived usefulness (PU) and a perceived ease of use (PeoU). Although since its formulation, the theory has been revised several times, the two constructs have remained the same. Hundreds of studies on TAM have happened in the developed countries, where the environment for technology acceptance is different from developing countries.

Literature on TAM, that was published recently, indicates slightly different on the importance of the two constructs in both developed and developing world. For example, Miller and Khera (2010) found out that, PU was much stronger predictor of intent to use a technology than PeoU. Furthermore, the study had tested five PU factors which are likely to influence the intent to use a technology: relevance, trust on content, visibility, social norm and knowledge domain. Each of these factors was hypothesized to predict the perceived usefulness across countries. They also found out that, relevance was the strongest factor followed by the trust on the content in influencing the cross-country usefulness of ICT solutions (Figure 1). Social norm and knowledge 


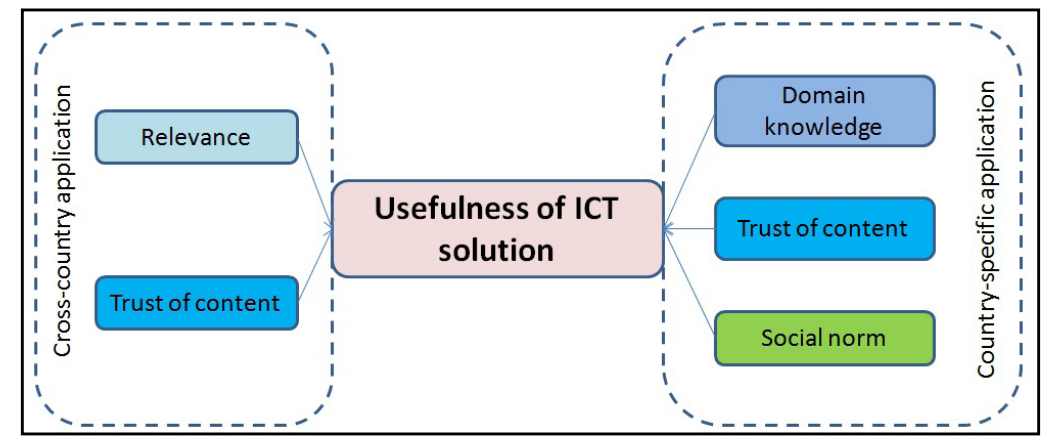

Source: Created from Miller and Khera, 2010

Figure 1: Factors influencing usefulness at national and international scales.

domain had a significant relationship at the country level while visibility was insignificant both within as well across countries.

Along this background, we are considering that stakeholders' involvement during designing and developing the technology is the key factor in perceived relevance of ICT for water basins management in the Southern Africa. Relevance is a multi-reference term which was formalized in the end of 1950's within the information science field.

However, with time, the term has found an application in individual disciplinary, trans-, cross- and multi-disciplinary studies. In the information science, relevance was originally defined by using two viewpoints: system-oriented and user oriented (Vickery, 1958). However, with applications of relevance expanded, alternative ways to relevance definition has been proposed. One of them is a logical way with reference to three parameters: A which stands for "Activity", $\mathrm{T}$ for "Thing" and $\mathrm{G}$ for "Goal" (Hjørland and Christensen, 2002). The three parameters should align in such a way that a meaningful contribution to the goal could be tracked (ibid). Relevance concept can thus, form a basis for result-based design and evaluation of an information system for water and other sectors. This study uses the TAM to theoretically and systematically understand the aggregate nature and trends of the relevance criteria of ICTs applied for the basin wide management of water resources in the Southern Africa. Specifically, the study sought to answer the following questions:

1. To what extent did the collected and reviewed literature on relevance were distributed in time and space?

2. How aggregate perceived relevance criteria related to ICT for water resources from selected literature were visualized between 2000 and 2015 ?

\section{Materials and methods}

The study focuses on water basins in the Southern Africa region especially on the ICT projects that were implemented in the Lake Victoria Basin, Limpopo River Basin, Zambezi River Basin, Orange River Basin and Okavango River Basin between 2000 and 2015 (Figure 2). This paper adopts a systematic review approach to data collection.

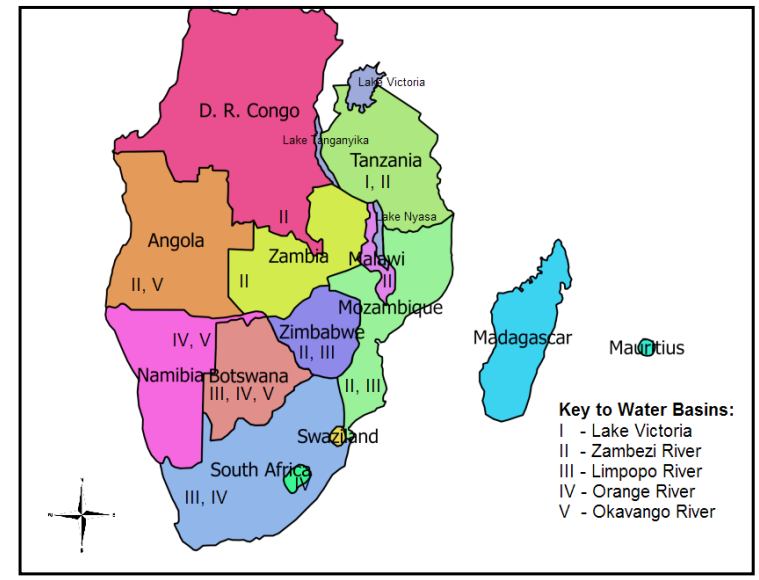

Source: Authors' construct aided by existing base maps

Figure 2: Specific water basins of the Southern Africa of which literature were cited.

Literature with academic view points from published and unpublished research reports were collected on projects conducted in five water basins in Southern Africa listed above. In addition, literature with practitioners view point as well as hybridviews complemented the listofpublications. The data collection flow chart with five key steps was adopted as a search strategy designed that focused on: (1) Generic literature related to integration ICTs, water basins, information technologies or information systems; (2) Filtration from step 
(1) of literature that were available between the years 2000 and 2015; (3) Filtration from step (2) of literature on issues that were related to the two domains of interest: ICT and water resources management; (4) Filtration from step (2) of literature on projects that were implemented solely on a particular basin or across the study areas; and (5) Filtration from step (2) of literature on relevance. Full texts of literature obtained in step (5) were then read in details to identify surfacing relevance criteria.

Step 1: Generic search for literature generated titles of over 400 documents including journals, books, reports, newsletters and bulletins. Gray literature was validated through tracking and assessing the publishers' websites and the cross-links.

Step 2: Skimmed abstracts revealed that 256 were published between years 2000 and 2015 .

Step 3: Among the literature obtained from step (2), 215 informed about ICTs for water resources either at theoretical or practical levels as well as at the regional and/or international scales.

Step 4: Out of literature in step (2), 121 informed about ICT related interventions for one or more of the target sites.

Step 5: At last, 75 out of literature in step (2) informed about the relevance in the contexts of interest, thus, were selected for detailed full-text readings in order to explore more about the perceived relevance criteria. The template composing of attribute of the relevance, explanation and examples was adopted in defining the criteria (Table 1).

\begin{tabular}{|l|l|l|}
\hline $\begin{array}{l}\text { Attribute } \\
\text { of relevance }\end{array}$ & Explanation & Examples \\
\hline Tool & $\begin{array}{l}\text { ICT tool developed } \\
\text { to support water } \\
\text { basin management } \\
\text { activities }\end{array}$ & $\begin{array}{l}\text { Web-based, mobile- } \\
\text { based tools as well as } \\
\text { combination of these } \\
\text { tools with community } \\
\text { radio }\end{array}$ \\
\hline Activity & $\begin{array}{l}\text { Water basin } \\
\text { management activity } \\
\text { supported by the tool }\end{array}$ & $\begin{array}{l}\text { Data collection } \\
\text { and processing, } \\
\text { data storage, as } \\
\text { well as information } \\
\text { dissemination }\end{array}$ \\
\hline Results & $\begin{array}{l}\text { Immediate, } \\
\text { intermediate } \\
\text { and a long term } \\
\text { effects on water } \\
\text { basin management. }\end{array}$ & $\begin{array}{l}\text { Enhanced information } \\
\text { sharing, reduced } \\
\text { conflicts on water } \\
\text { allocation, and eco- } \\
\text { equity sustainability }\end{array}$ \\
\hline
\end{tabular}

Source: Modified from Kontio, et al. (1996)

Table 1: Definition template of relevance criteria.

Summaries of the criteria and associated data were entered in IBM Statistical Package for Social
Sciences (SPSS) spreadsheet. Classifications, clustering and trend analyses were performed on the dataset. Analyzed results were further summarized into a visual sketch by using selected waves. A wave was an interval period of 5 years that was used in this study to simplify the trend analysis and visualization of perceived relevance criteria.

Classification of literature reviewed was done in four different classes representing four steps (2-5): First, by domain - technology-based domain (ICT/IS/IT) and a cross-disciplinary domain (Water/Environment/Agriculture). The second was by three waves each with different socio-technical characteristics. Thirdly, by basin, with crossbasin and specific basin based literature. Finally, by sources, focusing on either mainstream IS journals/books or other sources (Donors, host organizations, networks etc).

\section{Results and discussions}

\section{Classifications of literature reviewed}

Domains representation is shown by Figure $3 \mathrm{a}$. The majority of publications and other gray literature were cutting across the disciplines (53\%) while those from ICT disciplines constituted $47 \%$. This implied that, the socio-technical orientation of ICT solutions for water resources management had been well addressed.

The first wave from $2000 / 01$ to $2004 / 5$ was characterized by establishment or strengthening the formal organizations to address the challenges of a shared water resources in the region. Some of these were Okavango Commission (OKACOM), Orange-Senqu Commission (OSC) and The Limpopo Basin Commission (LBC). Activities such as strategic environmental assessments and strategic action plans were conducted in Okavango, Limpopo and Orange River basins (Nakayama, 2003). ICT solutions were mainly for decision support (Nakayama, 2003; Salewicz, 2003). They were targeting only key stakeholders that participated in decision making. For example, DSS and Trans-boundary Freshwater Dispute Database (TFDD) had the common purpose of preventing conflicts among riparian members. Only $21 \%$ of the literature reviewed fall within this wave (Figure 3b).

The second wave from $2004 / 05$ to $2009 / 10$ was characterized by increasing the computational power, booming mobile hardware and networks as well as the emphases towards more participatory ICT tools design and development (Jansky et al., 


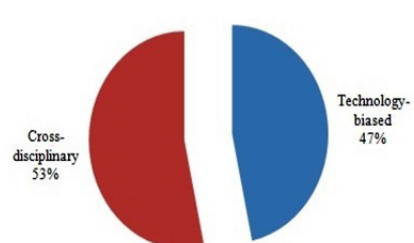

(a)

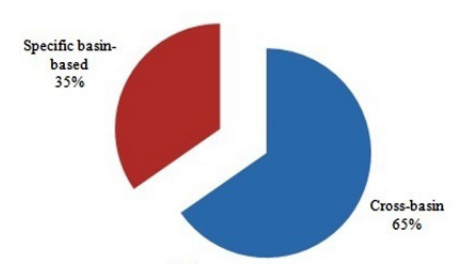

(c)

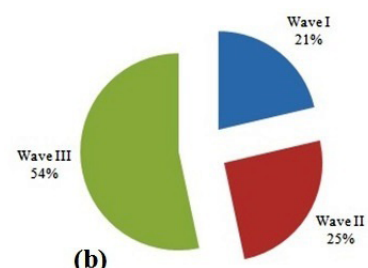

(b)
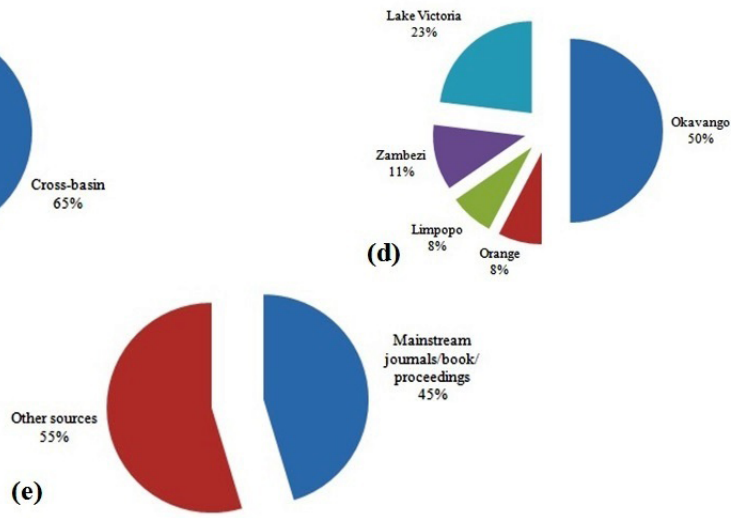

Source: own processing

Figure 3: Classifications of literature reviewed.

2005; Andersson et al., 2006; Hughes et al., 2006; Hermans et al., 2006; Macintosh and Whyte, 2008). There was more literature $(25 \%)$ in this wave compared to previous one. The third wave from 2010/11 to 2014/15 was characterized by even more advanced and accessible computing power, mobile hardware and networks. Socio-technical emphasis was not only on the stakeholders' involvement but also on the public engagements. During this wave, concepts like citizen science, citizen sensors and citizen actuation had emerged (Crowley et al., 2013). Majority of the publications and other gray literature (54\%) were found in this period.

Again the majority of literature reviewed was on cross-basin issues for about $65 \%$ while basinbased publications composed only 35\% (Figure 3c). In the latter category, Figure $3 d$ shows that Okavango river basin composed the greatest share by $50 \%$, followed by Lake Victoria basin by $23 \%$ and then the following river basins: Zambezi by $11 \%$, Orange and Limpopo (Each by $8 \%$ ). Majority of the literature reviewed were from other sources with $55 \%$ while those in the mainstream journals/books/proceedings were 29\% (Figure 3e).

\section{Trends and aggregation of relevance criteria}

The relevance of ICT for water resources management across the waves was determined by both social and technical criteria. Figure 4 shows the three waves, their corresponding yearly intervals and perceived extend of stakeholders' involvement. During wave I, web-based solutions were limited by bandwidth and network coverage; therefore, ICT solutions in the study area were predominantly desktop.

Cost effectiveness was therefore a major criterion. The accessibility to the information during this time was constrained by escalating costs, where access to web-based information, was limited to elites and above the average income earners. Bruch (2003), focused on comparison between cost related to access and usage of ICTs; and contributions in reducing costs related to conflicts in water basins. Apart from the cost effectiveness, other criteria were the quality of information and openness. The quality of information entailed the fitness for the purpose, reliability and legitimacy of information sources (ibid). Majority of ICT solutions for the water resources management during this period, were tools to support decision making (Bruch, 2003; Pereira et al., 2003; Salewicz, 2003). However, hardware constraints such as processing power, portability and storage capacity formed important criteria for consideration in acquisition of ICT solutions.

During wave II, the advancements of ICT in terms of hardware, software and networks changed the emphasis on the relevance criteria towards more participatory ones. Mobile devices including laptops, mobile phones and personal 


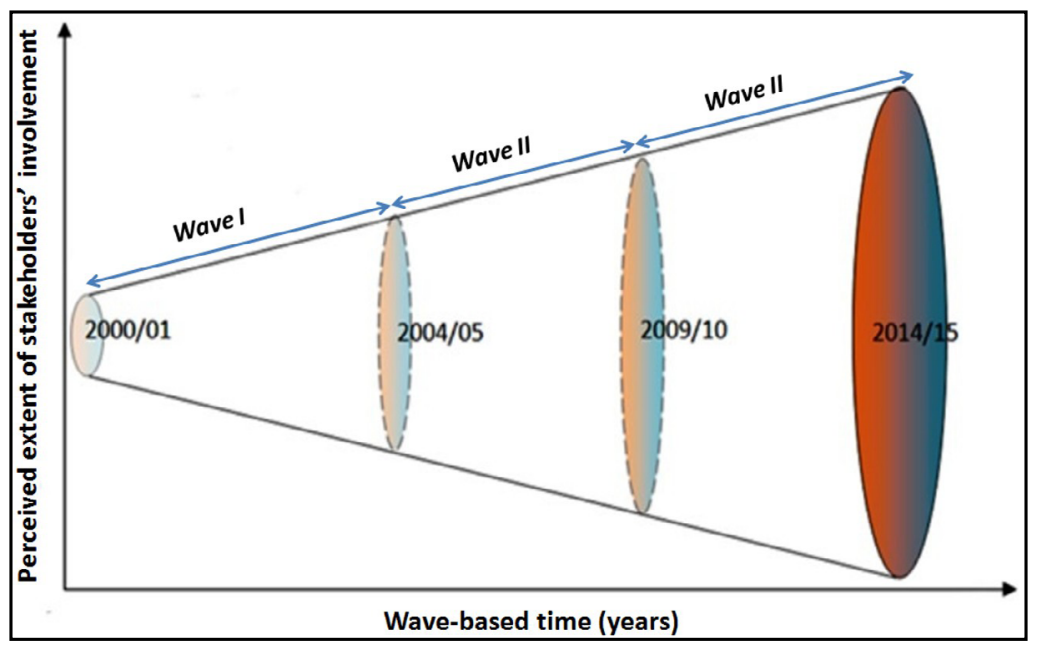

Source: own processing

Figure 4 :Trends and aggregation of usefulness criteria during different waves.

digital assistants (PDAs) as well as the improved mobile networks created an environment for ICT to support a wide spectrum of stakeholders in the water basin management. Alongside the enhanced portability, there was also an increase in the processing power and storage capacity, which improved the desktop-based solutions. The study by Jansky et al. (2005), revealed that the roles of information systems of informing, automating and transforming were discussed in line with a suggestion for a semi-automated web-based tool to support participatory data collection and management. Data were collected in the field and transferred to the web-servers for management and processing. Although Hughes et al. (2006) focused on Vietnam, the main criteria identified such as flexibility and adaptability apply in other areas including Southern Africa. While flexibility and credibility of tools that support participation or collaboration were emphasized, other criteria such as analytical capability and energy efficiency were suggested.

The most recent wave (wave III) suggested the relevance criteria that were more inclusive in terms of solving societal challenges by using the technology. Computing power continued to increase while portable and fast hardware that support big data storage increasingly became affordable. Software including mobile applications and open source also became accessible and networks coverage and costs became more inclusive. All these were opportunities to advance solutions by communities themselves. Relevance criteria in this phase were those which were related to supporting public engagement; where more actors were included in efforts to solve the water basin problems. Real-time capability of collecting, analyzing and sharing information; web-based solutions to facilitate integration; open standard and flexibility to facilitate access to new and existing databases, were important aspects for basin wide management. Other criteria such as redundancy, interoperability, open standards, quality assurance and multi-language user support had been listed in the literature belonging to wave III. The above criteria were emphasized where integration (combination) of software, hardware and/or procedures were attempted (Zarli et al., 2014; Vitolo et al., 2015; Badjana et al., 2015; Kralisch et al., 2013).

\section{Conclusion}

\section{Conclusion}

This study concludes that despite its huge geographical coverage, issues at the interface of ICTs and water resources in Southern Africa were limited in the literature. Systematic reviews and meta-analysis of the literature contents revealed their distribution across disciplinary domains, yearly wave intervals, the basin location and research outlets. The trends and aggregation nature of perceived relevance criteria of ICTs for water resources management has revealed changes driven by the technological advancement and societal challenges. There was a notable shift from more technological oriented criteria to socio-technical criteria, often with engagement of the public beyond the key stakeholders. The usage of the combination of hardware, software 
and languages with human-centered approaches were therefore broadly guiding analysis, design and implementation of ICT solutions for water basins in Southern Africa.

\section{Future work}

Results and conclusion from this paper may be part of the recipe for further studies intended to assess and evaluate relevance of ICTs applied for the management of water resources in the river and lake basins in Southern Africa as well as in similar environments in developing countries. The identified perceived relevance criteria, though not exhaustive, would help in designing a more robust template or framework to guide the output, outcome and impact evaluation of ICTs and thereby justify for current deployment status in the study area and beyond. Research towards a potential template and possibly framework is being undertaken by Department of Information Systems at The University of Dodoma. This study is expected to partly inform the said research process.

\section{Acknowledgements}

The authors wish to acknowledge the kind and material support from the German Academic Exchange Services (DAAD), Institute of Geography at Jena University, University of Dodoma and the organizers of the $19^{\text {th }}$ Conference on Information Systems for Agriculture and Forestry, Dresden Germany for reviewing and accepting this paper for presentation. However, findings and discussions presented in this paper are those of authors. Any shortcomings should not be associated with these institutions/organizations.

\section{Corresponding author:}

Mr. Hector Mongi (Ph.D. Student)

The University of Dodoma, P. O. Box 490 Dodoma, Tanzania

E-mail: hjmongi@yahoo.com

\section{References}

[1] Andersson, L., Wilk, J., Todd, M. C., Hughes, D. A., Earle, A., Kniveton, D., Layberry, R. and Savenije, H. H. G. (2006) "Impact of climate change and development scenarios on flow patterns in the Okavango River", Journal of Hydrology, Vol. 331, No. 1-2, pp. 43-57. ISSN 00221694.

[2] Badjana, H. M., Zander, F., Kralisch, S., Helmschrot, J. and Flügel, W. (2015) “An Information System for Integrated Land and Water Resources Management in the Kara River Basin (Togo and Benin)", International Journal of Database Management Systems (IJDMS), Vol. 7, No. 1, pp. 15-27, ISSN 0975-5705.

[3] Bruch, C. (2003) International waters in Southern Africa, In M. Nakayama (Ed.), International waters in Southern Africa, United Nations University Press. p. 317, ISBN 92-808-1077-4.

[4] Crowley, D. N., Curry, E. and Breslin, J. G. (2013) “Closing the loop - From citizen sensing to citizen actuation”, Proceedings of IEEE International Conference on Digital Ecosystems and Technologies, pp. 108-113. ISSN 21504938.

[5] Davis, F. D. (1989) "Perceived Usefulness, Perceived Ease of Use, and User Acceptance of Information Technology", MIS Quarterly, Vol. 13, No. 3, pp. 319-340. ISSN 0276-7783.

[6] Dodson, L. L., Sterling, S. and Bennett, J. K. (2012) Considering failure: eight years of ITID research. In Proceedings of the Fifth International Conference on Information and Communication Technologies and Development, ACM. ISBN 978-1-4503-1907.

[7] Heeks, R. (2003) Most e-Government-for-development projects fail: How can risks be reduced? iGovernment Working Paper Series, Institute for Development Policy and Management, University of Manchester. [Online] Available: unpan1.un.org/intradoc/groups/public/documents/NISPAcee/ UNPAN015488.pdf [Accessed: 12 November 2015].

[8] Hermans, L., Renault, D., Emerton, L., Perrot-Maître, D., Nguyen-Khoa, S. and Smith, L. (2006) Stakeholder-oriented valuation to support water resources management processes: Confronting concepts with local practice, UN-FAO. ISBN 92-5-105477-0. 
[9] Hjørland, B. and Christensen, S. F. (2002) "Work tasks and socio-cognitive relevance: a specific example", Journal of the American Society for Information Science and Technology, Vol. 53, No. 11, pp. 960-965. ISSN 1532-2890.

[10] Hughes, D. A., Andersson, L., Wilk, J. and Savenije, H. H. G. (2006) "Regional calibration of the Pitman model for the Okavango River", Journal of Hydrology, Vol. 331, No. 1-2, pp. 30-42. ISSN 00221694.

[11] Jansky, L., Sklarew, D. M. and Uitto, J. I. (Eds) (2005) Enhancing public participation and governance in water resources management: Conventional Approaches and Information Technology, UN University Press. ISBN 9280811207.

[12] Kgathi, D. L., Kniveton, D., Ringrose, S., Turton, A. R., Vanderpost, C. H. M., Lundqvist, J. and Seely, M. (2006) "The Okavango; a river supporting its people, environment and economic development", Journal of Hydrology, Vol. 331, No. 1-2, pp. 3-17. ISSN 00221694.

[13] Kontio, J., Caldiera, G. and Basili, V. R. (1996) "Defining Factors, Goals and Criteria for Reusable Component Evaluation", Proceedings of CASCON '96 Conference, November 12-14, Toronto, Canada. [Online] Available: https://www.cs.umd.edu/ basili/publications/proceedings/P73.pdf [Accessed: 8 September 2015].

[14] Kralisch, S., Zander, F. and Flügel, W. (2013) "OBIS - a Data and Information Management System for the Okavango Basin”, Biodiversity and Ecology, Vol. 5, p. 214-220. ISSN 1613-9801.

[15] Macintosh, A. and Whyte, A. (2008) "Towards an evaluation framework for eParticipation", Transforming Government: People, Process and Policy, Vol. 2, No. 1, p. 16-30. ISSN 1750-6166.

[16] Miller, J. and Khera, O. (2010) "Digital Library adoption and the technology acceptance model: A cross-country analysis", The Electronic Journal of Information Systems in Developing Countries, Vol. 40, No. 6, p. 1-19. ISSN 1681-4835.

[17] Nakayama, M. (2003) Introduction: Opportunities and risks. In M. Nakayama (Ed.), International Waters in Southern Africa, United Nations University Press, p. 317. ISBN 92-808-1077-4.

[18] Pereira, Â. G., Rinaudo, J., Jeffrey, P., Blasques, J., Quintana, S. C., Courtois, N., Funtowicz, S. and Petit, V. (2003) "ICT Tools to Support Public Participation in Water Resources Governance \& Planning: Experiences from the Design and Testing of a Multi-media platform", Journal of Environmental Assessment Policy and Management, Vol. 5, No. 3, p. 395-420. ISSN 1464-3332.

[19] Salewicz, K. A. (2003) Building the bridge between decision-support tools and decision-making, In M. Nakayama (Ed.), International Waters in Southern Africa. Tokyo: UN University Press, p. 317. ISBN 92-808-1077-4.

[20] van Koppen, B., Namara, R., Safilios-Rothschild, C. (2005) Reducing Poverty through Investments in Agricultural Water Management: Poverty and Gender Issues and Synthesis of Sub-Saharan Africa Case Study Reports. IWMI Working paper No. 101, 2005, p. 66. ISBN 92-909-0615-4.

[21] Vickery, B. C.(1959) The structure of information retrieval systems. Proceedings of the International Conference on Scientific Information, p. 1275-1290. pp. 1662. ISBN 0-309-57421-8. DOI: 10.17226/10866

[22] Vitolo, C., El-Khatib, Y., Reusser, D., Macleod, C. J. a., \& Buytaert, W. (2015) "Web Technologies for Environmental Big Data". Environmental Modelling \& Software, Vol. 63, p. 185-198. ISSN 1364-8152. DOI 10.1016/j.envsoft.2014.10.007.

[23] Wholey, J. S., Hatry, H. P., Newcomer, K. E. (Eds) (2010) Handbook of practical program evaluation, $3^{\text {nd }}$ ed., pp. 700. Wiley \& Sons Publications. ISBN 978-0-470-52247-9.

[24] Zarli, A., Rezgui, Y., Belziti, D., and Duce, E. (2014) Water Analytics and Intelligent Sensing for Demand Optimised Management: The WISDOM Vision and Approach. In $16^{\text {th }}$ Conference on Water Distribution System Analysis, WDSA, pp. 1050-1057. Elsevier Inc. ISBN 978-1-63439-782-7. 